\title{
ULTRASOUND GUIDED TRANS-SARTORIAL INTERNAL SAPHENOUS NERVE BLOCK IN PATELLAR CHONDROPATHY
}

\author{
Vaamonde Lorenzo, Lucía; Galván Ortiz de Urbina, Marta; Archanco Olcese, Miguel; \\ Cuenca González, Concepción; Garvín Ocampos, Lucía.
}

Hospital Universitario Clínico San Carlos, Madrid, Spain

Internal saphenous nerve block is used for analgesia in arthroscopic interventions, saphenous neuralgia and refractory knee pain. The approach can be trans-sartorial, sub-sartorial, lateral femoral condyle and below knee.

Our purpose with this work is to evaluate the effectiveness of the technique in the control of pain, the functionality of the knee and the degree of patient satisfaction.

A 57-year- old woman attending a rehabilitation visit due to right knee pain of internal and medial predominance of 2 years of evolution. She referred mild improvement after pharmacological and physiotherapy treatment.

Personal history: Addison's disease and lumbar schwannoma.

Nuclear Magnetic Resonance showed grade III patellar chondropathy and degenerative internal meniscopathy.

Visual Analogue Scale (VAS): resting 7/10, in activity 9/10. Knee injury and Osteoarthritis Outcome Score (KOOS) 20\%.

Ultrasound-guided trans-sartorial internal saphenous nerve block was performed with $5 \mathrm{ml}$ of levobupivacaine $(2.5 \mathrm{mg} / \mathrm{ml})$.

She was asked and evaluated monthly and at 3 months using VAS for pain at rest and in activity; also functional limitation of the knee by KOOS and the degree of satisfaction through Roles and Mausley scale.
Results at one month and at three months:

- In VAS for pain at rest was 0/10, activity was 0/10.

- In KOOS the result obtained was $87.5 \%$.

- And her answer for Roles and Maudsley scale was 1 that correspond to an excellent result.

Conclusion: Ultrasound-guided internal (trans-sartorial) saphenous nerve block is a therapeutic option in refractory knee pain by reducing pain, improving knee function, and increasing patient satisfaction.
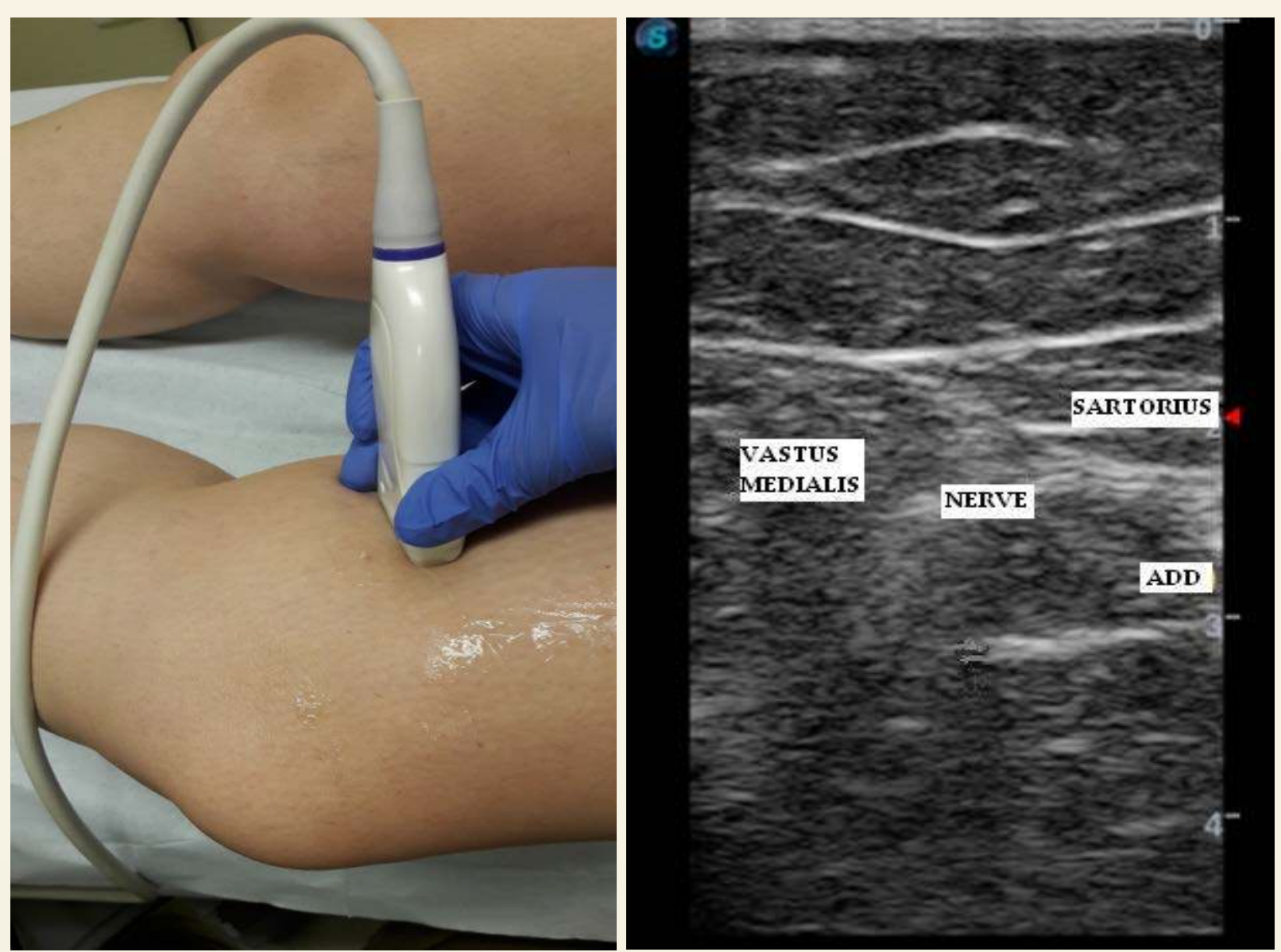

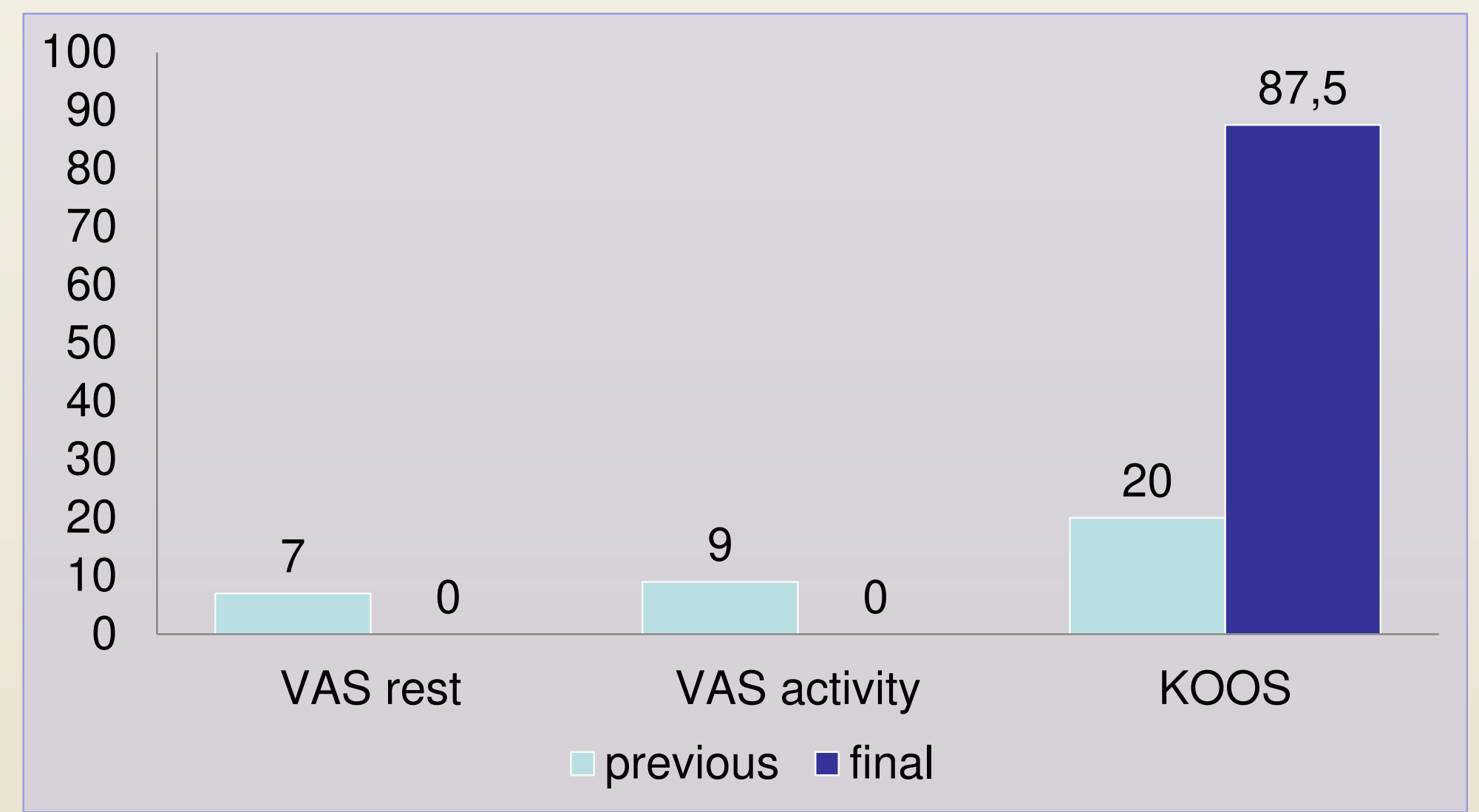

